\title{
OFICINAS AMBIENTAIS DA ÁREA DE PROTEÇÃO AMBIENTAL DE GUAPI- MIRIM E DA ESTAÇÃO ECOLÓGICA DA GUANABARA (RJ): ATRAINDO A COMUNIDADE ÀS UNIDADES DE CONSERVAÇÃO ATRAVÉS DE CAPACITAÇÕES
}

\author{
Andressa Pieroni Santana ${ }^{1}$ \\ Juliana Cristina Fukuda ${ }^{2}$
}

\section{RESUMO}

Com três edições anuais desde 2011, a Semana de Oficinas Ambientais da APA de GuapiMirim e da ESEC da Guanabara já trouxe à sede dessas unidades de conservação cerca de 420 pessoas. Parte desse público nunca havia estado ali nem sabia da existência dessas áreas protegidas. Ao todo ano foram ministradas vinte e sete oficinas, sobre diversos temas. Os profissionais que conduzem as oficinas atuam geralmente em entidades parceiras e aceitam o convite para realizar as oficinas gratuitamente. Na terceira edição do evento foi realizada paralelamente às oficinas a Mostra de Vídeos do Circuito Tela Verde. A divulgação sobre o evento é feita através de lista de endereços eletrônicos, mídias sociais e cartazes nas comunidades da região. Nas duas últimas edições foram colocados à disposição transporte a partir de alguns pontos da APA de Guapi-Mirim. O custo médio de cada semana de evento foi de $\mathrm{R} \$ 336,00$.

Palavras-chave: Uso público, população local, evento, APA de Guapi-Mirim, ESEC da Guanabara

\begin{abstract}
With three annual editions since 2011, Environmental Workshops Week of Guanabara Ecological Station and Guapi-Mirim Environmental Protected Area has brought to the headquarters of these protected areas about 420 people. Part of this audience had never been there or knew about these protected areas. Altogether twenty-seven workshops on various topics were held. The professionals who lead the workshops usually work in partner organizations and accept the invitation to hold the workshops for free. In the third edition of the event it was held the Green Screen Circuit of Videos Show in parallel to the workshops. The event disclosure is made through electronic addresses list, social media and posters in local communities. In the last two editions transportation from some points of Guapi-Mirim EPA was made available. The average cost of each event week was $\mathrm{R} \$ 336,00$.
\end{abstract}

Keywords: public use, local people, event, Guapi-Mirim Environmental Protected Area, Guanabara Ecological Station

\footnotetext{
${ }^{1}$ Bióloga - Núcleo de Gestão Integrada da APA de Guapi-Mirim e da Estação Ecológica da Guanabara - Instituto Chico Mendes de Conservação da Biodiversidade (ICMBio). BR-493, km 12,8, Guapimirim, RJ, CEP 25940000. http://www.icmbio.gov.br/apaguapimirim. E-mail: andressa.santana@icmbio.gov.br

${ }^{2}$ Bióloga, analista ambiental - Núcleo de Gestão Integrada da APA de Guapi-Mirim e da Estação Ecológica da Guanabara - ICMBio. E-mail: juliana.fukuda@icmbio.gov.br
} 


\section{INTRODUÇÃO}

A Área de Proteção Ambiental (APA) de Guapi-Mirim, criada pelo Decreto 90.225/1984, está situada na região metropolitana do Rio de Janeiro, abrangendo parte dos municípios de Magé, Guapimirim, Itaboraí e São Gonçalo. A APA é constituída por áreas públicas e áreas privadas. Localizada no recôncavo da Baía de Guanabara, é componente da Região Hidrográfica da Baía de Guanabara, abrangendo uma área total de aproximadamente 14 mil ha. Desta extensão, cerca de 6200 ha $(44,7 \%)$ correspondem aos manguezais, em diferentes estados de conservação e regeneração, que ocupam a faixa costeira dos citados municípios, drenada pelos baixos cursos dos rios Guapi-Macacu, Caceribu e Guaxindiba. Da área total da unidade, 2800 ha $(19,6 \%)$ são em terra firme e os demais 5 mil ha $(35,7 \%)$ englobam a seção das águas da baía em frente aos mangues. A região de manguezais recebe os principais rios que desembocam na Baía de Guanabara - cerca de $70 \%$ das contribuições de água fluvial de toda essa baía - e representa o último reduto contínuo desse ecossistema nessa bacia hidrográfica. (Ibama, 2004).

Em 2006, a proteção de ecossistemas de grande relevância ambiental foi reforçada pela criação da Estação Ecológica (ESEC) da Guanabara, criada pelo decreto s/n $n^{0}$ de 2006, com cerca de 2 mil hectares, abrangendo os municípios de Guapimirim e Itaboraí. É a área mais conservada de toda a Baía de Guanabara (ICMBio, 2012). A gestão dessas duas unidades de conservação é realizada pelo Instituto Chico Mendes de Conservação da Biodiversidade, e de maneira integrada, compartilhando recursos humanos, materiais e financeiros.

A existência da APA de Guapi-Mirim e da ESEC Guanabara (Figura 1), tenta assegurar a manutenção das condições naturais de trechos da baía, viabilizando a sua recuperação como ecossistema. Garante ainda a vida na Baía de Guanabara, representada pela cadeia biológica constituída por microrganismos, crustáceos, moluscos, camarões, peixes e mamíferos. Assegura, também, a permanência e sobrevivência de uma população humana que mantém uma relação estreita com o ambiente, vivendo de seus recursos naturais e mantendo ainda características muito tradicionais no convívio com o ambiente.

Considerando que um dos objetivos diretos das unidades de conservação é a promoção da educação ambiental (BRASIL, 2000), a gestão da APA de Guapi-Mirim desde o seu início teve a preocupação de promover ações nesse sentido, ainda que de maneira não-sistematizada (IBAMA, 2004). Entretanto, a partir de 2007 aumentou-se o interesse para a instalação de empreendimentos industriais na região - com destaque para o Complexo Petroquímico do Rio de Janeiro (Comperj) e suas obras associadas - fazendo com que a força de trabalho de gestão da APA Guapi-Mirim e da ESEC Guanabara se envolvesse, principalmente, no acompanhamento dos processos de licenciamento ambiental desses empreendimentos. A partir de 2009, com melhor estrutura operacional, retomaram-se mais intensamente as atividades de educação ambiental (FUKUDA et al., 2011). 

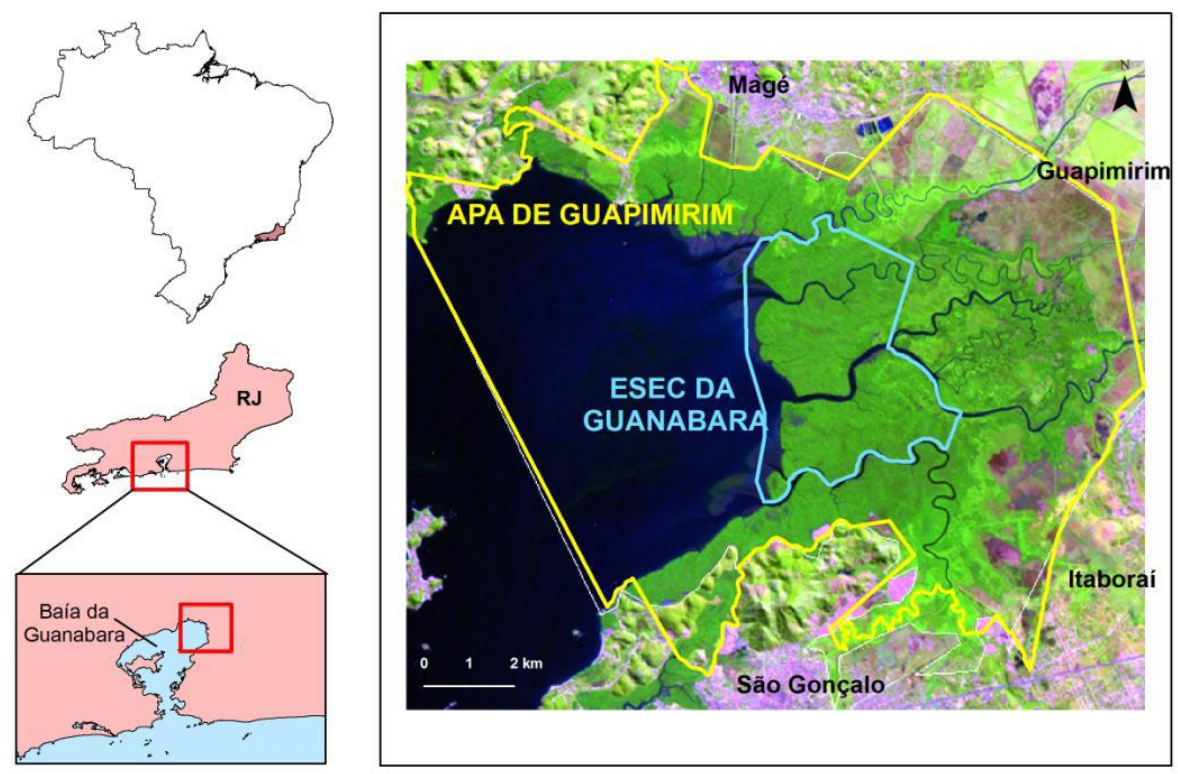

Figura 1 - Localização da APA de Guapi-Mirim e da ESEC Guanabara

Na linha da educação não-formal, em 2010 e 2011, realizamos algumas sessões do projeto Cine Ambiental. O objetivo era projetar filmes voltados ao grande público mas que tivesse questões ambientais no enredo e que pudessem suscitar discussões entre os moradores da APA de Guapi-Mirim. Foram realizadas tanto sessões na sede das UC - com transporte gratuito saindo de diferentes bairros - como nas próprias comunidades, em diferentes horários e dias da semana. Entretanto, a participação foi considerada baixa (de 5 a 20 pessoas por sessão). Algumas delas avaliaram que a maioria das pessoas possuía televisão e aparelho de DVD em casa, e tinham a possibilidade de comprar cópias de vídeos a preços irrisórios no centros urbanos.

O plano de manejo da APA de Guapi-Mirim indica que as ações de educação ambiental devem visar "a informação da população, a capacitação pela busca de melhor qualidade de vida na Baía de Guanabara e a proteção dos recursos ambientais e culturais da APA" (IBAMA, 2004). Sorrentino (1998) defende que "o fortalecimento da autonomia local, e da compreensão/ação global, aberta a todos os cidadãos da Terra, passa por opções de tecnologias socialmente e ecologicamente apropriadas, passa pelo investimento no desenvolvimento de conhecimentos que as viabilizem".

Pádua e Tabanez (1998) argumentam que "uma nova ética, com paradigmas em consonância com um mundo mais harmônico, depende da apropriação de valores que levem ao exercício pleno da cidadania. A importância de se trabalhar valores é, portanto, uma constatação que deve ser considerada em programas de educação ambiental. Novos valores significam um primeiro passo para mudanças que ocasionam um interesse uma autoconfiança que podem levar ao envolvimento em assuntos conservacionistas”. 
Em 2011 e 2012, no "Diagnóstico da Educação Ambiental nas Escolas da região da APA de Guapi-Mirim", apenas $11 \%$ dos professores declararam ter conhecimento sobre essa unidade de conservação. Apesar de apenas aproximadamente 4,5\% dos professores da região terem indicado que gostariam de ter capacitação em educação ambiental (FUKUDA et al., 2011), pensamos que a realização de atividades interessantes, focadas especialmente para professores (mas também aberta a outros interessados), poderia atraí-los e aumentar o conhecimento local sobre as duas UCs federais da região.

Então, em 2012, a partir da oferta de realização de serviço voluntário por uma estudante de Biologia, aliada à necessidade de atuarmos mais junto às comunidades locais, foi organizada a I Semana de Oficinas Ambientais da APA de Guapi-Mirim e da ESEC da Guanabara, que ocorreu de 24 a 27 de julho daquele ano (propositadamente durante as férias escolares), na própria sede dessas UCs. Neste primeiro ano o evento contou com os seguintes temas: Artesanato com materiais reutilizáveis, Horta (três turmas) e Ciclo e desperdício de água.

Nos dois anos seguintes o evento foi realizado novamente, mas com apoio de parceiros para ministrar as oficinas, de voluntários para a organização do evento, e da própria instituição para viabilizar lanche e transporte para os participantes.

A segunda edição do evento ocorreu de 15 a 19 de julho de 2013. Os temas das oficinas foram: Comunicação - redação e vídeo, Hortas domésticas; Artesanato de objetos decorativos com materiais reutilizáveis; Primeiros socorros e Teatro.

A terceira edição ocorreu entre os dias 28 de julho e $1^{\circ}$ de agosto de 2014 , e abordou temas de Primeiros Socorros, Banheiro Seco, Rádio Comunitária, Hortas e Compostagem e Teatro do Oprimido. Neste ano, paralelamente às oficinas, realizamos a Mostra de Vídeos do Circuito Tela Verde. Participam dessa lista filmes selecionados pelo Ministério do Meio Ambiente e distribuídos às Salas Verdes (como é o caso da sede APA de Guapi-Mirim / EE da Guanabara) e aos espaços que concorrem para ser pontos de exibição.

Buscamos sempre oferecer temas que sejam de interesse da população local, com atividades teórico-práticas. Antes de cada oficina, é feita uma breve apresentação sobre o ICMBio e sobre as unidades de conservação em questão.

A cada dia da semana, duas turmas - uma por período (manhã e tarde) - participaram de apresentação sobre o ICMBio e as duas UCs locais e, em seguida, os parceiros deram início às discussões e realização da prática.

O objetivo deste trabalho é apresentar dados sobre as três edições já realizadas do evento "Oficinas Ambientais da APA de Guapi-Mirim e da ESEC da Guanabara", discutindose alguns de seus aspectos. 


\section{METODOLOGIA}

O presente trabalho foi realizado através de:

a) descrição das diferentes oficinas realizadas nas três edições da Semana de Oficinas Ambientais da APA de Guapi-Mirim e da ESEC da Guanabara,

b) análise das listas de presença dos participantes nas oficinas,

c) análise das avaliações realizadas pelos participantes na última edição do evento

$\mathrm{Na}$ avaliação realizada em 2014, os participantes foram requeridos a responder a questões rápidas sobre si, sobre o ICMBio e as UCs em questão, e sobre as oficinas.

Os resultados foram tabulados e analisados a fim de melhorar a qualidade das próximas edições do evento.

\section{RESULTADOS}

A I Semana de Oficinas Ambientais da APA de Guapi-Mirim e da ESEC da Guanabara contou com 45 participantes, que atenderam as oficinas conforme a Figura 2.

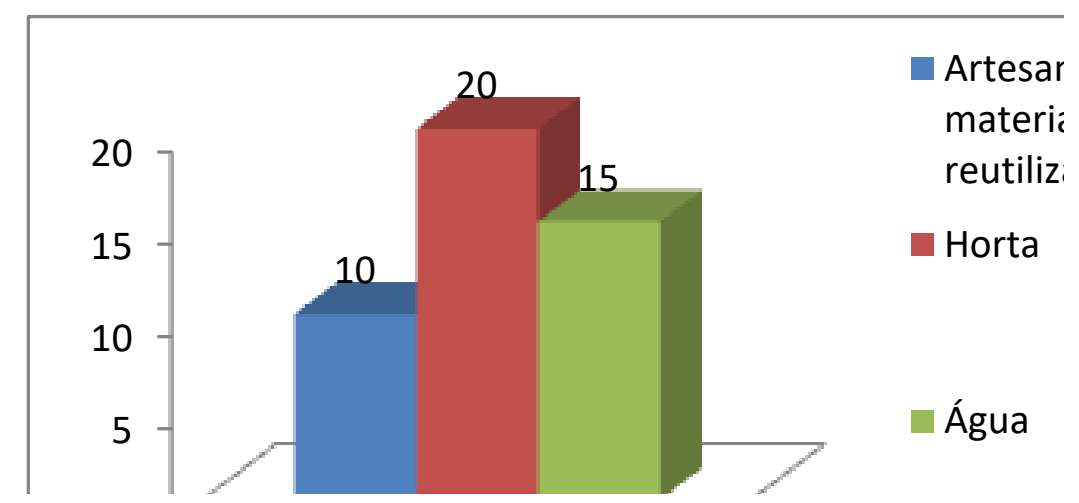

Figura 2 - Número de participantes por tema das oficinas em 2012

O evento abordou, através da Oficina de Artesanato com Materiais Recicláveis, inserir o diálogo e a modificação de materiais reutilizáveis em novos objetos e buscou, nos participantes, um novo olhar sobre antigos costumes e condicionantes adquiridas ao longo de uma vida de consumos e excessos. A oficina foi ministrada pela voluntária e então estudante de biologia da UFMG, Gabriela Novais.

$\mathrm{Na}$ Oficina de Horta, que teve três turmas divididas em dois dias, destacou-se a importância de uma alimentação saudável, a qualidade dos alimentos e disponibilidade dos mesmos, enfatizando-se como é fácil e também benéfico possuir um espaço horta dentro das realidades familiares, para adquirir alimentos saudáveis, de origem conhecida e livre de agrotóxicos. A oficina foi ministrada pelos agrônomos da Emater - Magé, Mauricio Monteiro e Edison Rodrigues.

A oficina sobre Ciclo e Desperdício de Água teve como intuito mostrar para os participantes da região dados sobre o tema e ideias de aplicação de demonstrações sobre o 
assunto. Nesta oficina foram abordados diversos pontos, como a importância dos manguezais para a região metropolitana do Rio de Janeiro e na vida da Baía de Guanabara, a importância da água para os seres humanos, os conflitos da água e os mecanismos de preservação desse bem. A oficina também foi ministrada pela voluntária Gabriela Novais.

Em 2013, com mais estrutura de planejamento - três voluntárias participaram da organização - foi realizada a II Semana de Oficinas Ambientais, que agregou 183 participantes, entre crianças, adolescentes e adultos. Na Figura 3 é apresentada a quantidade de pessoas em cada dia (ou seja, em duas oficinas daquele tema). As prefeituras de Itaboraí e Guapimirim cederam ônibus em um dos dias para trazer os interessados desses municípios.

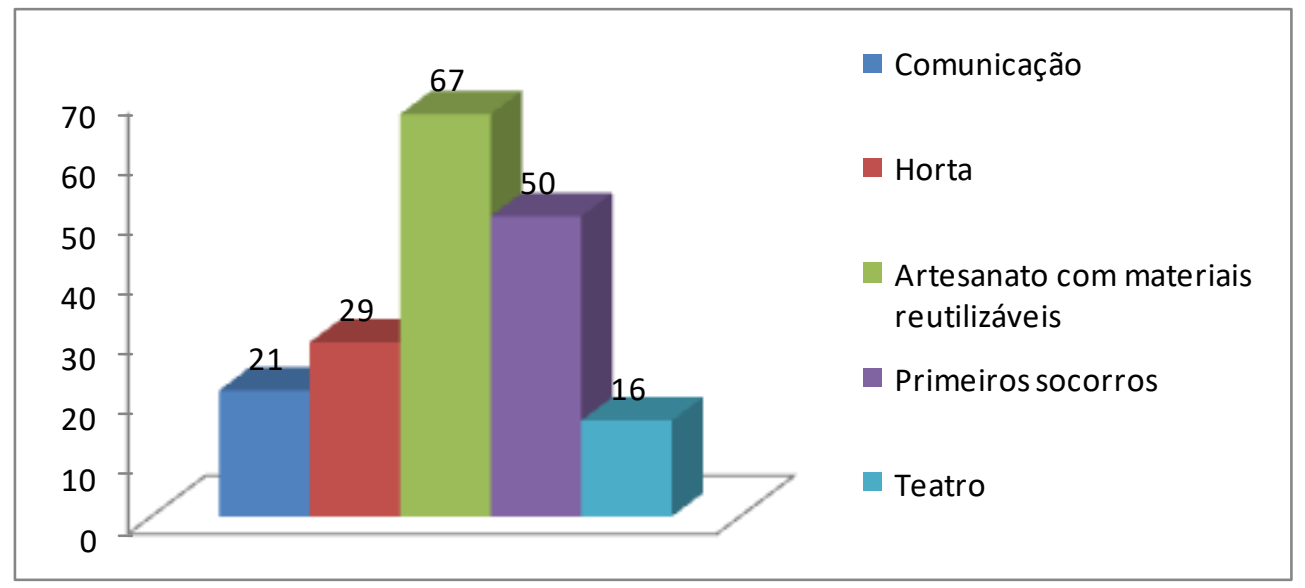

Figura 3 - Número de participantes por tema das oficinas em 2013

As oficinas de redação e vídeo foram ministradas por integrantes do Escritório Executivo do Mosaico Central Fluminense: Francisco Pontes Miranda, Dione Storck e Felipe Raibolt da Silva. Mostrou-se como é feita uma reportagem, inclusive com edição de vídeos. A capacitação despertou em alguns participantes a vontade de colocar o aprendizado em prática. Surgiu, assim, o Núcleo de Comunicação da APA Guapi-Mirim e da ESEC da Guanabara, formado por quatro voluntários.

Na oficina de Hortas domésticas, conduzida por técnicos da Emater Magé, foi abordada a importância das hortaliças na alimentação, ação das vitaminas e o cozimento para reter ao máximo o valor nutritivo. Foram mencionados problemas como aplicação de agrotóxico para o solo, as plantas e as pessoas, as vantagens dos alimentos produzidos em casa em relação àqueles do mercado, e as técnicas e datas certas de plantio, colheita e manejo.

A oficina de Artesanato Com Materiais Reutilizáveis tratou, primeiramente, do problema do uso de recursos naturais e da geração de resíduos sólidos, sendo importante repensar nossas práticas e reduzir o consumo. Mostrou-se como é possível usar a criatividade e gerar renda com embalagens de leite tipo tetrapak, garrafas pet, latas de conservas. Cada participante fez um vaso e caixas porta-objeto a partir de caixas de leite.

No treinamento em primeiros socorros, que foi conduzido pelo Corpo de Bombeiros, explicou-se que em geral o cidadão reage erroneamente diante de uma situação de 
emergência, e que todos são responsáveis para ajudar. Durante as explicações, foram sendo demonstradas algumas manobras importantes, e ao final foram feitas práticas de salvamento com os participantes.

No último dia das oficinas, jovens do grupo teatral All Star, formado por adolescentes de uma escola estadual da região, contaram como ele surgiu e, na sequência, apresentaram técnicas de representação, principalmente para trabalhar a timidez e o improviso. Criou-se logo um clima descontraído, e os participantes foram se entregando aos exercícios. Nesse caso, a oficina foi muito importante para valorizar e incentivar a iniciativa desse grupo.

Na III Semana de Oficinas Ambientais, o evento contou com cinco voluntários para auxiliar na organização. Foram 177 participantes distribuídos em dez oficinas, que abordaram os temas de Primeiros Socorros, Banheiro Seco, Rádio Comunitária, Hortas e Compostagem e do Teatro do Oprimido (Figura 4). A prefeitura de Guapimirim disponibilizou uma kombi para trazer participantes interessados daquele município.

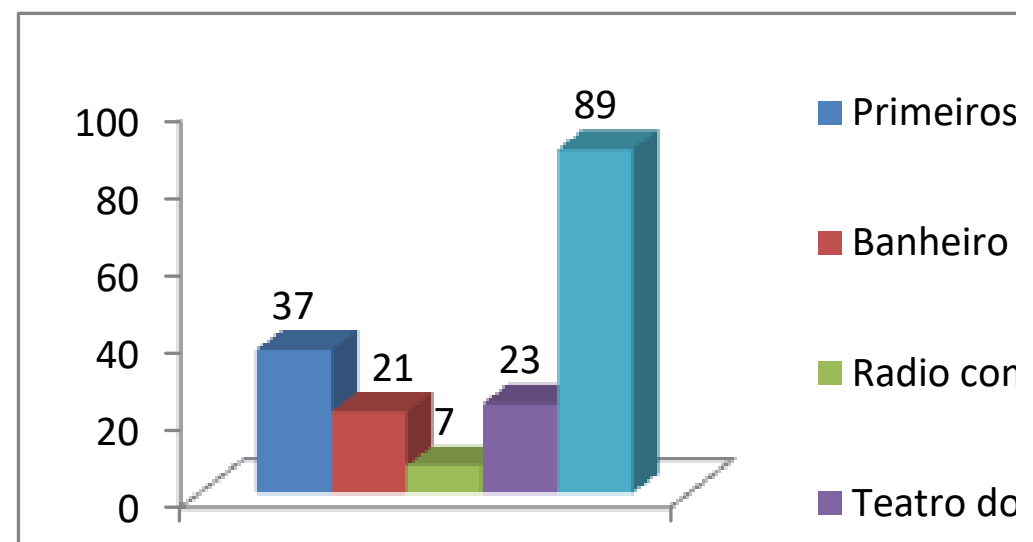

Figura 4 - Número de participantes por tema das oficinas em 2014

Nesse ano, paralelamente às oficinas, foi realizada a Mostra de Vídeos do Circuito Tela Verde, onde foram projetados filmes dessa iniciativa do Ministério do Meio Ambiente e cuja programação para os cinco dias foi divulgada juntamente com a Semana de Oficinas. A ideia era que participantes que viessem para as oficinas de manhã ficassem para a mostra à tarde e vice-versa. Para que isso ocorresse, foi providenciado um lanche reforçado, que foi servido ao final de cada oficina no turno da manhã.

O sargento Sadi da Silva Qarqart, do Batalhão do Corpo de Bombeiros do município de Magé, apresentou de forma prática e interativa técnicas de primeiros socorros como já desenvolvidas nas oficinas anteriores.

As oficinas de Banheiro Seco, conduzida pelo permacultor Carlos Henrique Nicolau da Silva (Curumim), que ensinou as técnicas e a construção do banheiro seco, apresentando uma forma ecológica de aproveitamento dos dejetos humanos.

Nas oficinas de Rádio Comunitária foram ensinadas técnicas radiofônicas de web rádio em comunidades e em unidades escolares como ferramenta da Educomunicação. As 
atividades foram alavancadas pela equipe das Ondas do Ambiente, que é um programa da Secretaria de Estado do Ambiente do RJ (SEA), composta por Ludi Um e Vitor Sales.

Um dia da programação foi voltado ao Teatro do Oprimido, realizado pelo analista ambiental Olivar Bendelak, com exercícios e jogos, com objetivo de usar o teatro como ferramenta de trabalho político, social, ético e estético, contribuindo para a transformação social.

Pela Mostra de Vídeos do Circuito Tela Verde passaram cerca de 120 pessoas, na maioria estudantes de escolas públicas da região. A estratégia de manter o público tanto para as oficinas quanto para os vídeos não funcionou - nenhum participante permaneceu o dia todo a fim de atender aos dois eventos.

A Figura 5 ilustra a evolução da quantidade do público participante nas oficinas ao longo dos três últimos anos. Avaliamos que na terceira edição houve uma leve diminuição na quantidade devido à mostra de vídeos, que dividiu o público.

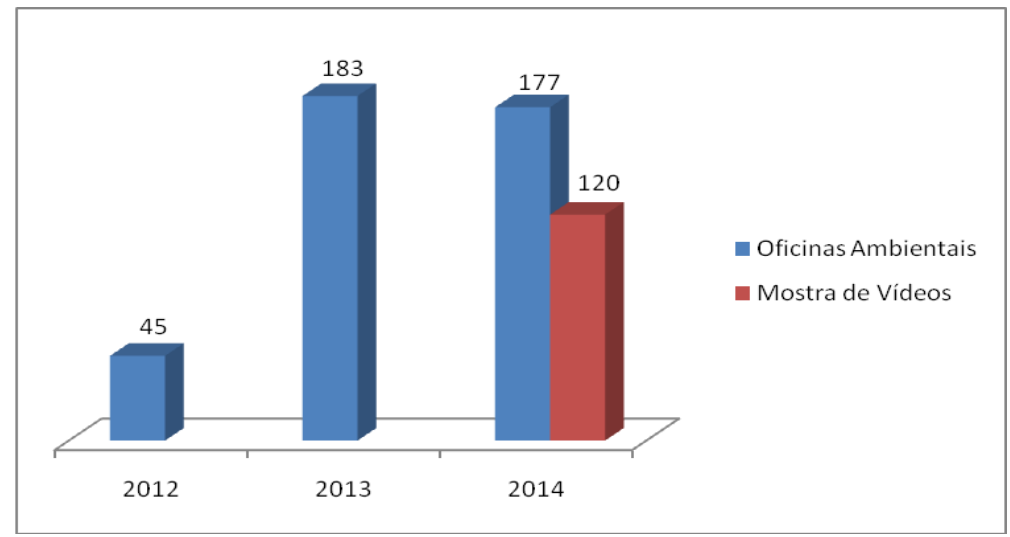

Figura 5 - Número total de participantes por oficinas (2012, 2013 e 2014)

Os custos para compra de materiais para as oficinas e de um lanche simples para os participantes, nas três edições do evento foram arcados pela Fundação SOS Mata Atlântica através do Fundo Guanabara ${ }^{3}$. Além disso, foi servido almoço aos palestrantes, custeado pelo ICMBio. Os gastos aproximados em cada ano foram, cronologicamente, de R\$222,00, $\mathrm{R} \$ 351,00$ e $\mathrm{R} \$ 436,00$, aproximadamente (Figura 6). Consideramos que os custos são bastante baixos em relação ao impacto que o evento tem na região. Percebe-se também que os investimentos têm sido proporcionais à quantidade que têm participado das atividades.

\footnotetext{
${ }^{3}$ O Fundo Guanabara é um fundo fiduciário mantido desde 2008 pela Fundação SOS Mata Atlântica com objetivo de dar suporte às ações gerenciais da ESEC da Guanabara e da APA de Guapi-Mirim.
} 


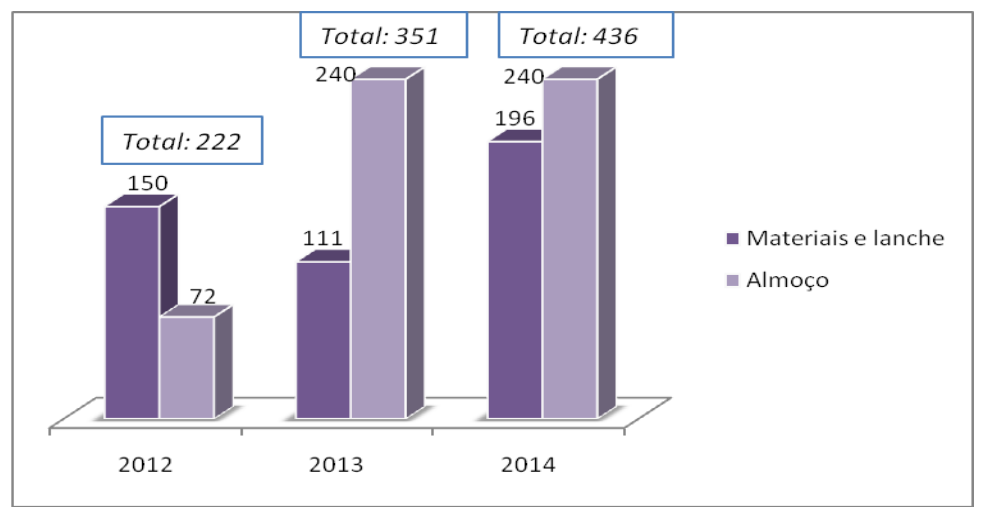

Figura 6 - Custos dos eventos por ano, em reais

\section{Avaliação do evento pelos participantes em 2014}

Dos 177 participantes na terceira edição do evento, 110 responderam todo ou parte do questionário de avaliação.

Desses participantes, $53 \%$ eram do gênero feminino e $47 \%$, do masculino. Em relação à idade, $63 \%$ tinham entre 10 e 30 anos. Todas as faixas etárias estão ilustradas na Figura 7. Esses dados demonstram o interesse dos jovens por capacitações, mas a presença de pessoas de diversas faixas etárias mostra que os temas são de interesse geral em relação à idade, e também ao gênero.

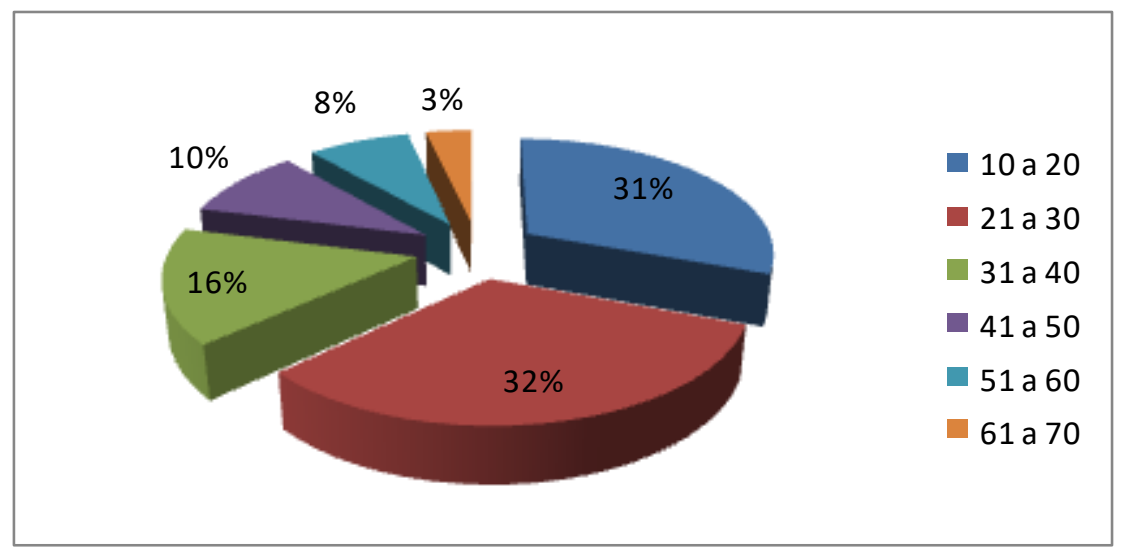

Figura 7 - Idade dos participantes que responderam à avaliação em 2014

Em relação ao conhecimento prévio quanto ao ICMBio, $90(81,8 \%)$ já tinham ouvido falar dessa instituição.

Em relação às unidades de conservação aqui trabalhadas, $53(48,2 \%)$ já tinham ao menos ouvido falar das duas UCs, $38(35,4 \%)$ tinha alguma noção somente sobre a APA e 19 $(17,3 \%)$ declarou que nunca tinha ouvido falar de nenhuma das duas UCs. Essa porcentagem é bem maior que as levantada com 144 professores das escolas região em 2011 - 11\% delas tinham ouvido falar da APA e apenas 0,7\% sobre a ESEC (FUKUDA et al., 2011). Apesar da 
diferença de público e de situação, isso pode ser um indício do aumento do conhecimento da população local quanto a essas UCs.

Em relação ao meio de divulgação pelo qual ficaram sabendo do evento, a maioria $(65 \%)$ teve conhecimento através de indicação por conhecidos. As demais respostas estão apresentadas na Figura 8.

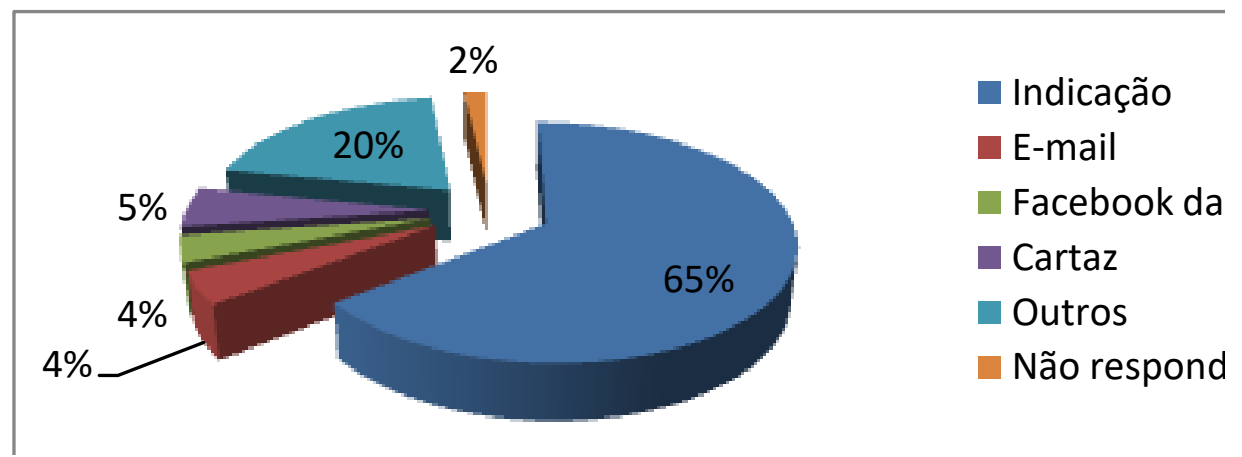

Figura 8 - Meio pelo qual os participantes ficaram sabendo do evento

Os meios de transporte utilizados pelos participantes foram: particular (44\%), transporte cedido pela prefeitura (39\%) e público (17\%). Esses dados mostram a importância em se conseguir o apoio das prefeituras para cessão de transporte, que viabiliza vinda de pessoas de menor renda.

De forma geral, a terceira edição do evento foi muito bem avaliada pelos participantes, sendo que na média dos itens questionados, $71 \%$ consideraram o evento muito bom, e 13,5\%, bom. Na Figura 9 estão ilustradas as avaliações dadas a cada quesito indagado.

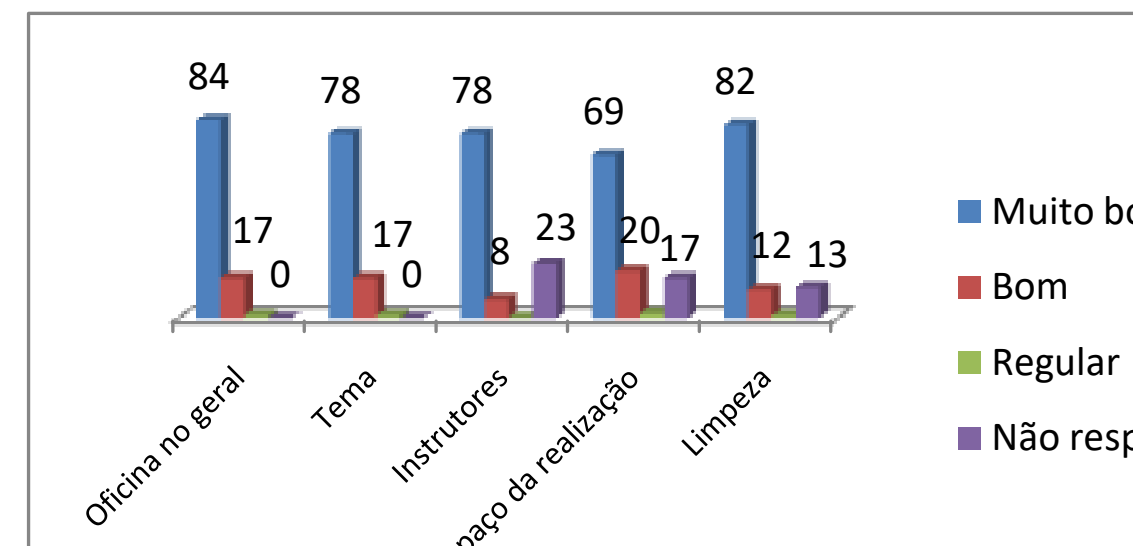

Figura 9 - Avaliação geral da oficina de acordo com os 110 participantes, em números absolutos

Sobre a vontade de participar do evento em 2015, 56\% responderam que pretendem participar. Os $44 \%$ restantes não responderam. 


\section{CONCLUSÃO}

A realização da Semana de Oficinas Ambientais da APA de Guapi-Mirim e da ESEC da Guanabara, que tem um custo bastante modesto, tem possibilitado diversos ganhos:

- promover capacitação gratuita a pessoas de diferentes idades, origens geográficas e classes sociais

- promover a troca de experiências entre técnicos e moradores locais, e desses entre si

- provocar o pensamento crítico dos visitantes em relação a questões socioambientais

- absorver a oferta de interessados ao serviço voluntário para apoiar a organização do evento

- atrair novos voluntários

- divulgar a importância dessas duas UCs

- divulgar as atribuições e as atividades desenvolvidas pelo ICMBio

Visando dar continuidade a esse evento, em 2015 as oficinas deverão ocorrer nas comunidades, que tem como objetivo levar essas capacitações mais perto dos bairros semirurais da APA de Guapi-Mirim, situados em Magé, Guapimirim, Itaboraí, e São Gonçalo. Prevemos a montagem de uma estrutura simples para que algumas voluntárias possam realizar atividades educativas com as crianças, possibilitando às pessoas que teriam que cuidar dos filhos, netos, sobrinhos, etc, a participar das oficinas. Dessa maneira acreditamos aumentar nossa interação com as comunidades, promovendo capacitações e provocando a reflexão, sobre temas de interesse deles. E idealizamos a criação de uma rede de conhecimento, trocas de experiências e de transformação de velhos conceitos entre os maiores usuários e beneficiários dessa unidade de conservação.

\section{AGRADECIMENTOS}

Às entidades e profissionais parceiros, tais como: EMATER - Escritório Local Magé, Corpo de Bombeiros, prefeituras municipais, ONG Bantu Brasil, Secretaria de Estado do Ambiente, Mosaico Central Fluminense. Aos voluntários, que foram essenciais para a organização dos eventos. À Fundação SOS Mata Atlântica, para aquisição de materiais e de lanche. Aos professores e outras lideranças locais, que auxiliaram na divulgação e mobilização de participantes para as oficinas. Aos chefes e toda a equipe da APA de GuapiMirim e da ESEC da Guanabara, que sempre incentivaram e deram suporte à realização dos eventos.

\section{REFERÊNCIAS BIBLIOGRÁFICAS}

BRASIL. Lei n⿳ 9.985, de 18 de julho de 2000. Regulamenta o art. 225, § 1o, incisos I, II, III e VII da Constituição Federal, institui o Sistema Nacional de Unidades de Conservação da Natureza e dá outras providências. 
FUKUDA, J.C., FARIA, C.S., COELHO, B.H. da S., MELlO, T.F. de, MUNIZ, M.B., SANTANA, A.P., PAIVA, L.G. e SILVA, M.L. da. Diagnóstico sobre os Professores nas Escolas da Região da Área de Proteção Ambiental de Guapimirim (RJ) em relação à Educação Ambiental. Anais eletrônico do Seminário Brasileiro Sobre Áreas Protegidas e Inclusão Social. Manaus, 2011.

IBAMA (Instituto Brasileiro do Meio Ambiente e dos Recursos Naturais Renováveis). Plano de Manejo da Área de Proteção Ambiental de Guapimirim. Brasília, 2004.

ICMBIO (Instituto Chico Mendes de Conservação da Biodiversidade). Plano de Manejo da Estação Ecológica da Guanabara. Brasília, 2012.

PÁDUA, S.M. e TABANEZ, M.F. Participação Comunitária: Elemento Chave na Proteção de Unidades de Conservação. In: Cascino, F.; Oliveira, J.F. de e Jacobi, P. (orgs.). Educação, Meio Ambiente e Cidadania: reflexões e experiências. Secretaria de Estado do Meio Ambiente de SP/ Coordenadoria de Educação Ambiental, 1999, p.27 a 29.

SORRENTINO, M. De Tbilisi a Tessaloniki, A Educação Ambiental no Brasil. In: Cascino, F.; Oliveira, J.F. de e Jacobi, P. (orgs.). Educação, Meio Ambiente e Cidadania: reflexões e experiências. Secretaria de Estado do Meio Ambiente de SP/ Coordenadoria de Educação Ambiental, 1999, p.20 a 24. 